\title{
Efficacy of Palbociclib and Endocrine Treatment in Heavily Pretreated Hormone Receptor-positive/HER2-negative Advanced Breast Cancer: Retrospective Multicenter Trial
}

\author{
Atakan Demir1, Nil Molinas Mandel2, Semra Paydas³, Gökhan Demir1, Özlem Er1, Nazım Serdal Turhal4, \\ Sevil Bavbek 5 , Yeşim Eralp1, Pınar Mualla Saip6, Emine Nilüfer Güler7, Adnan Aydıner6, \\ Başak Oyan Uluç1, Sadettin Kılıçkap7, Necdet Üskent4, Nuri Karadurmuş8, Mehmet Ali Kaplan9, \\ Mustafa Teoman Yanmaz10, Hacer Demir11, Özkan Alan12, Taner Korkmaz1, Polat Olgun13, \\ Özlem Sönmez Uysal1, Kadri Altundağ14, Şeyda Gündüz15, Meral Günald116, Murat Sar15, \\ İsmail Beypınar11, Gül Başaran1 \\ ${ }^{1}$ Department of Medical Oncology, Acıbadem University, İstanbul, Turkey \\ ${ }^{2}$ Clinic of Oncology, American Hospital, İstanbul, Turkey \\ ${ }^{3}$ Department of Medical Oncology, Çukurova University School of Medicine, Adana, Turkey \\ ${ }^{4}$ Clinic of Oncology, Anadolu Medical Center Hospital, Kocaeli, Turkey \\ ${ }^{5}$ Self-employed, İstanbul, Turkey \\ ${ }^{6}$ Department of Medical Oncology, İstanbul University Oncology Institute, İstanbul, Turkey \\ ${ }^{7}$ Department of Medical Oncology, Hacettepe University School of Medicine, Ankara, Turkey \\ ${ }^{8}$ Clinic of Medical Oncology T.C. Ministry of Health Gülhane Training and Research Hospital, Ankara, Turkey \\ ${ }^{9}$ Department of Medical Oncology, Dicle University School of Medicine, Diyarbakır, Turkey \\ ${ }^{10}$ Şişli Memorial Hospital, İstanbul, Turkey \\ ${ }^{11}$ Department of Medical Oncology Afyon Kocatepe University School of Medicine, Afyon, Turkey \\ ${ }^{12}$ Tekirdağ State Hospital, Tekirdağ, Turkey \\ ${ }^{13}$ Near East University Hospital, Lefkoşa, TRNC \\ ${ }^{14}$ Self-employed, Ankara, Turkey \\ ${ }^{15}$ Antalya Memorial Hospital, Antalya, Turkey \\ ${ }^{16}$ Clinic of Medical Oncology, Florya Medical Park Hospital, İstanbul, Turkey
}

Background: The synthesis of CDK4/6 inhibitors with endocrine treatment in two series of treatment has been widely accepted as the standard for patients with estrogen receptor-positive metastatic breast cancer. In spite of this, the activity of CDK4/6 inhibitors in patients with metastatic breast cancer who have progressed despite receiving multiple lines of treatment is not well understood.

Aims: To report the activity and safety of a CDK4/6 inhibitor (palbociclib) in patients in whom at least three lines of treatment for $\mathrm{ER}^{+}$metastatic breast cancer had failed.

Study Design: Multicenter retrospective observational cohort study. Methods: In this retrospective observational cohort study, we included 43 patients who received palbociclib after at least three lines of systemic treatment for $\mathrm{ER}^{+} / \mathrm{HER} 2^{-}$metastatic breast cancer.

Results: The median progression-free survival in our population was 7 months $\left(25^{\text {th }}-75^{\text {th }}\right.$ percentile, $\left.4-10\right)$, and the median overall survival was 11 months $\left(25^{\text {th }}-75^{\text {th }}\right.$ percentile, 6-19). Although there were some adverse events, palbociclib was generally well tolerated, so dose reduction was needed for only six patients $(14 \%)$.

Conclusion: The efficacy of palbociclib among heavily treated hormone receptor-positive/HER2 ${ }^{-}$patients with advanced breast cancer was acceptable in terms of clinical benefit, and it was generally well tolerated among this population.

Keywords: Breast cancer, CDK4/6 inhibitors, palbociclib

\footnotetext{
Address for Correspondence: Atakan Demir, Department of Medical Oncology, Acıbadem University, İstanbul, Turkey Phone: +90 $5062979770 \quad$ e-mail: atakandemir85@gmail.com ORCID: orcid.org/0000-0002-1940-4086 Received: 27 November 2019 Accepted: 13 January 2020 • DOI: 10.4274/balkanmedj.galenos.2020.2019.11.143 Available at www.balkanmedicaljournal.org Cite this article as:

Demir A, Molinas Mandel N, Paydas S, Demir G, Er Ö, Turhal NS, Bavbek S, Eralp Y, Saip PM, Güler EN, Aydıner A, Oyan Uluç B, Kılıçkap S, Üskent N, Karadurmuş N, Kaplan MA, Yanmaz MT, Demir H, Alan Ö, Korkmaz T, Olgun P, Sönmez Uysal Ö, Altundağ K, Gündüz Ş, Günaldı M, Sarı M, Beypınar İ, Başaran G. Efficacy of Palbociclib and Endocrine Treatment in Heavily Pretreated Hormone Receptor-positive/HER2-negative Advanced Breast Cancer: Retrospective Multicenter Trial Balkan Med J 2020;37:104-7

${ }^{\circ}$ Copyright 2020 by Trakya University Faculty of Medicine / The Balkan Medical Journal published by Galenos Publishing House.
} 
Breast cancer (BC) is a major cancer in women. Despite the numerous therapeutic options that are available, it remains incurable, earning it the notorious reputation of being the second most common cause of cancer death in Western populations, following lung cancer (1). BC is a heterogeneous disease and has a variety of subgroups according to clinical, pathological, and molecular features (2).

Approximately $80 \%$ of all BC cases are estrogen receptor-positive $\left(\mathrm{ER}^{+}\right)$/human epidermal growth factor receptor 2 negative (HER2-). According to current guidelines, sequential endocrine therapy (ET) is the main treatment recommendation for premenopausal and postmenopausal women with ER ${ }^{+} / \mathrm{HER} 2-$ stage 4 BC (except for extensive visceral involvement) $(3,4)$. Resistance to ET (acquired or de novo) will develop in the vast majority of these cases during therapy (5). Cyclin-dependent kinases and mammalian target of rapamycin (mTOR) signaling pathways are the main mechanism of resistance to ET (6). Currently, the most commonly recommended therapeutic options to overcome ET resistance are mTOR inhibition (everolimus) and CDK4/6 inhibition (palbociclib, abemaciclib, and ribociclib) (7-9).

The combination of CDK4/6 inhibitors with ET in two series of treatment has been widely accepted as the standard treatment for patients with $\mathrm{ER}^{+}$metastatic breast cancer (mBC) (1012). However, the activity of $\mathrm{CDK} 4 / 6$ inhibitors in patients with $\mathrm{mBC}$ progressing after multiple treatment lines is not well known. In this multicenter retrospective study, we report the activity and safety of a CDK4/6 inhibitor (palbociclib) in patients for whom at least three lines of treatment for $\mathrm{ER}^{+} \mathrm{mBC}$ had failed.

\section{MATERIALS AND METHODS}

In this retrospective observational cohort study conducted between 14 September 2015 and 22 November 2019, we included 43 patients from different medical oncology clinics in Turkey. Patients received palbociclib after at least three lines of systemic treatment for $\mathrm{ER}^{+} / \mathrm{HER} 2^{-} \mathrm{mBC}$ (confirmed at diagnosis or on the basis of a metastatic lesion). Patients using fulvestrant or aromatase inhibitors with palbociclib were included in the study. Baseline was defined as the date of the first dose of palbociclib. All patients provided written informed consent to participate in the study, and ethical approval was given by our institution's ethics committee (12 September 2019; approval no.: 2019-14/34).

The main outcomes of this trial were overall survival (OS) and progress-free survival (PFS). OS was determined from the date of initiation of therapy until death or last visit date. PFS was the time window from the beginning of treatment to radiological progression, death, or last visit date. We also report the frequency of adverse events related to therapy (e.g., neutropenia, anemia, thrombocytopenia, diarrhea).

We included patients with $\mathrm{mBC}$ who progressed according to response evaluation criteria in solid tumors (RECIST) criteria despite at least three lines of standard therapy. Our exclusion criteria were as follows: radiotherapy, surgery, or systemic treatment within 2 weeks; past medical history of cardiovascular disease (arrythmias including atrial fibrillation, torsades de pointes, long or short QT interval, prior myocardial infarction, coronary artery bypass grafting, heart failure, and pulmonary embolism); hypersensitivity of palbociclib; and suicidal behavior.

\section{Statistical analysis}

The data were analyzed using descriptive statistical methods. Continuous variables are given as mean \pm standard deviation, and categorical variables are given as percentages. Kaplan-Meier curves were created to determine OS and PFS. IBM SPSS Statistics version 21 software (IBM, Armonk, NY, USA) was used to analyze the data and generate graphical content.

\section{RESULTS}

The median age of patients was 51 years $\left(25^{\text {th }}-75^{\text {th }}\right.$ percentile, 44-58). All patients were diagnosed with $\mathrm{mBC}$, and 30 patients $(69.7 \%)$ were initially in stages I-III. All patients were $\mathrm{ER}^{+}$, and five $(11.6 \%)$ were $\mathrm{ER}+$ /progesterone receptor-negative. Most of the patients were pathologically classified as having invasive ductal carcinoma $(n=41 ; 95.3 \%)$. All patients were given at least three lines of treatment for $\mathrm{mBC}$, including chemotherapy and ET. For most of the patients, adjuvant ET was tamoxifen $(n=19$; $44.1 \%)$. Other combinations were as follows: letrozole $(n=6$; $13.9 \%)$ and anastrozole $(n=3 ; 6.9 \%)$. Five patients $(11.6 \%)$ had received both a steroidal and a nonsteroidal AI. Fulvestrant was used in $39.5 \%$ of patients $(n=17)$ before palbociclib/AI. Twentyone premenopausal women had undergone surgical or medical castration as part of combination hormone therapy. Only one patient had been treated with the exemestane/everolimus combination. Most of the patients $(55 \% ; n=23)$ had received sequential monochemotherapy with standard drugs, including taxanes, capecitabine, gemcitabine, and anthracyclines, whereas a small minority had received combination chemotherapy regimens such as capecitabine/docetaxel; fluorouracil, doxorubicin, and cyclophosphamide; doxorubicin/docetaxel; or a combination of both approaches. The baseline characteristics of patients in the study cohort are outlined in Table 1 .

According to RECIST criteria, no complete response was observed. Six patients $(13.9 \%)$ had a partial response, 28 patients $(65.1 \%)$ had stable disease, and 9 patients $(21 \%)$ had progressive disease. The disease control rate was $79 \%$, and the objective response rate was $13.9 \%$. The median PFS in our population was 7 months $\left(25^{\text {th }}-75^{\text {th }}\right.$ percentile, 4-10) (Figure 1), and the median OS was 11 months (25th-75th percentile, 6-19) (Figure 2 ). All deaths in our study cohort were associated with disease progression.

Although there were some side effects, palbociclib was generally well tolerated. As a result, dose reduction was needed for only 6 patients (14\%). The most common nonhematological side effect was nausea $(n=30 ; 69.7 \%)$. Elevated transaminase levels were also frequent $(n=25 ; 58.1 \%)$. Grade 3 neutropenia occurred in 12 patients $(27.9 \%)$, and febrile neutropenia was seen in 2 patients (4\%) (Table 2). 


\section{DISCUSSION}

CDK4/6 inhibitors are a critical step in the abolishment of ET resistance among $\mathrm{ER}^{+} / \mathrm{HER} 2^{-}$patients. Many phase II and III clinical trials have been carried out to investigate the efficacy and safety of CDK4/6 inhibitors among this population (8-11). In the PALOMA-1 trial, the median PFS was 20.2 months in the letrozole/ palbociclib arm and 10.2 months in the letrozole/placebo arm [hazard ratio, 0.488; 95\% confidence interval (CI), 0.319-310.748; $\mathrm{p}=0.0004]$ (13). Similarly, in the PALOMA-2 trial, median PFS was 24.8 months in the palbociclib/letrozole arm and 14.5 months in

TABLE 1. Baseline characteristics of patients in the study cohort

\begin{tabular}{lc}
\hline Age (years) $\left(25^{\text {th }}-75^{\text {th }}\right.$ percentiles) & $51(44-58)$ \\
Hormone receptor status & $\mathrm{n}=38(88.3 \%)$ \\
$\mathrm{ER}^{+} / \mathrm{PR}^{+}$ & $\mathrm{n}=5(11.6 \%)$ \\
$\mathrm{ER}^{+} / \mathrm{PR}^{-}$ & \\
Histological diagnosis & $\mathrm{n}=41(95.3 \%)$ \\
Ductal invasive & $\mathrm{n}=2(4.6 \%)$ \\
Lobular invasive & \\
Stage of disease & $\mathrm{n}=30(69.7 \%)$ \\
Stages I-III & $\mathrm{n}=13(30.3 \%)$ \\
Stage IV & $\mathrm{n}=22(51.1 \%)$ \\
Menopausal status (postmenopausal patients) & \\
Adjuvant endocrine therapy & $\mathrm{n}=19(44.1 \%)$ \\
Tamoxifen & $\mathrm{n}=6(13.9 \%)$ \\
Letrozole & $\mathrm{n}=3(6.9 \%)$ \\
Anastrozole & \\
Site of metastasis & $\mathrm{n}=11(25.6 \%)$ \\
Bone & $\mathrm{n}=27(62.8 \%)$ \\
Visceral & $\mathrm{n}=5(11.6 \%)$ \\
Brain & \\
\hline ER: estrogen receptor, PR: progesterone receptor & \\
\hline
\end{tabular}

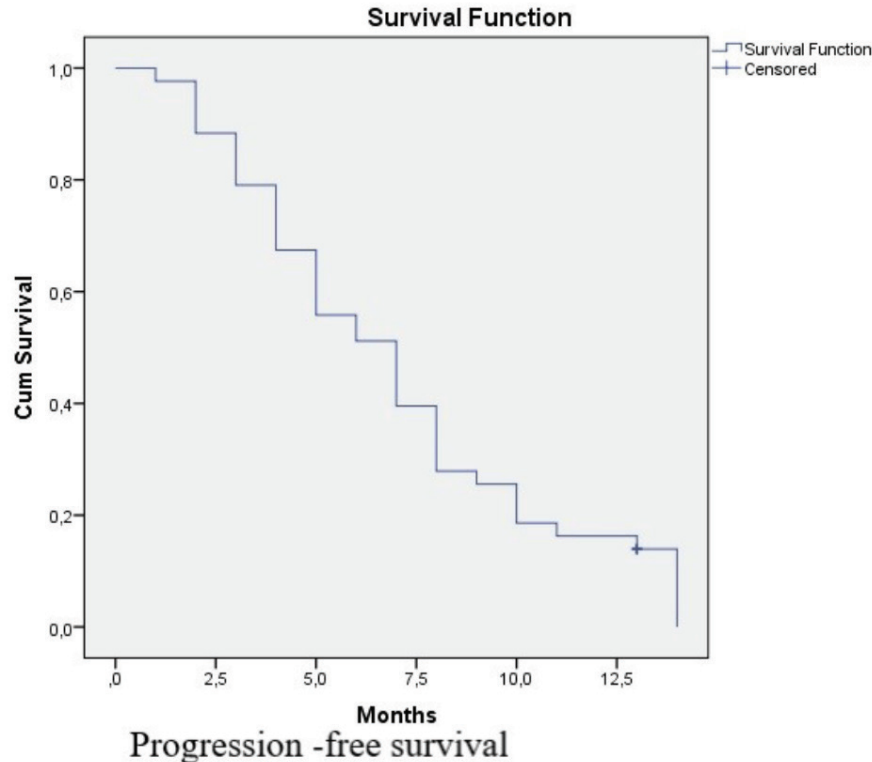

FIG. 1. Overall Survival graphic for the whole group by Kaplan Meier curve [median OS: 11 months $\left(25^{\text {th }}-75^{\text {th }}\right.$ percentile, 6-19)]. the letrozole/placebo arm (hazard ratio, $0.58 ; 95 \%$ CI, 0.46-40.72; $\mathrm{p}<0.001$ ) (14). The PALOMA-3 trial was performed to evaluate the efficacy of the combination of palbociclib and fulvestrant among 521 patients with hormone receptor-positive $\mathrm{mBC}$ as a secondline treatment option. The palbociclib-fulvestrant combination improved PFS significantly compared with the placebo-fulvestrant arm (9.2 vs 3.8 months; $\mathrm{p}<0.001$ ) (9). Another CDK4/6 inhibitor, abemaciclib, was also tested in second-line treatment in the MONARCH 2 trial. The results were promising; the abemaciclibfulvestrant combination prolonged PFS significantly (median PFS, 16.4 vs 9.3 months; $\mathrm{p}=0.001$ ) (11).

In spite of CDK4/6 inhibitors their being well investigated among $\mathrm{ER}^{+} / \mathrm{HER} 2^{-}$patients, there are no large phase 3 studies showing efficacy after treatment. Ban et al. (15) published a retrospective analysis of 24 heavily pretreated patients with $\mathrm{ER}^{+} / \mathrm{HER} 2^{-} \mathrm{mBC}$. All patients in their trial received a minimum of four lines of treatment for $\mathrm{mBC}$, including chemotherapy and ET. They reported that $58.3 \%$ of patients achieved stable disease, and median PFS was 4.8 months and median OS was 11 months. They reported that grade III neutropenia occurred in $54.1 \%$ of patients $(n=13)$, grade IV neutropenia in $12.5 \%$ of patients $(n=3)$, and grade III thrombocytopenia occurred in $12.5 \%$ of patients $(n=3)$. The most commonly reported treatment-related nonhematologic adverse event was nausea $(12.5 \% ; n=3)$. These side effects were consistent with our trial (15). In our trial, more patients achieved stability

TABLE 2. Adverse events during palbociclib treatment

\begin{tabular}{lc} 
Elevated transaminases & $25(58.1 \%)$ \\
Any neutropenia & $12(27.9 \%)$ \\
Febrile neutropenia & $2(4 \%)$ \\
Nausea any grade & $30(69.7 \%)$ \\
Dose reduction due to side effects & $6(14 \%)$ \\
\hline
\end{tabular}

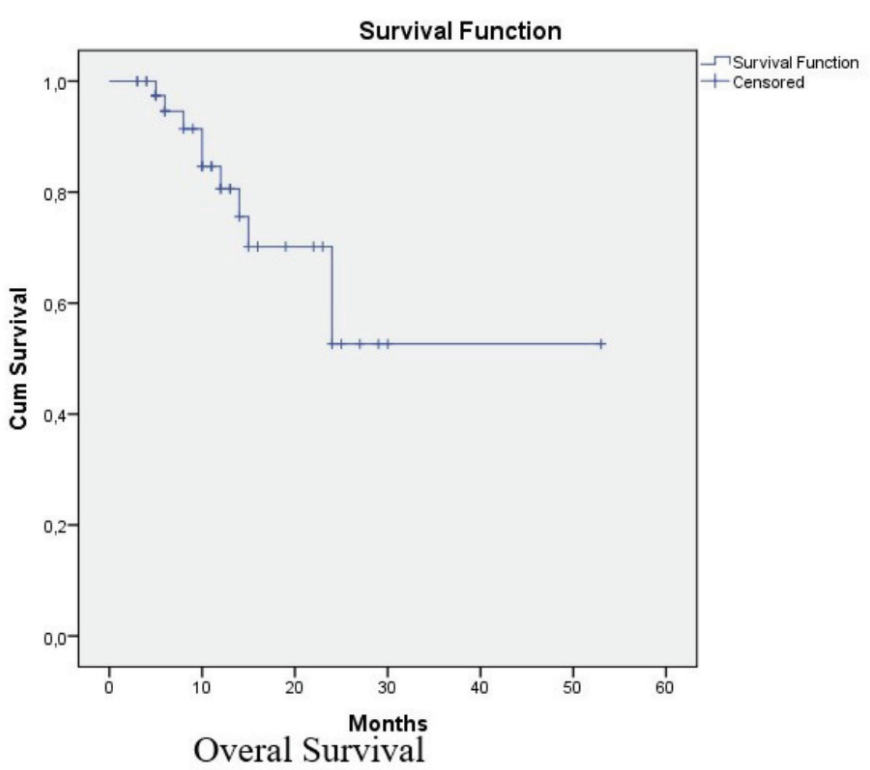

FIG. 2. Progression-free Survival graphic for the whole group by Kaplan Meier curve [median PFS:7 months $\left(25^{\text {th }}-75^{\text {th }}\right.$ percentile, 4-10)]. 
than in the trial by Ban et al. (15) (65.1\% vs 58.3), and PFS was a bit longer in our trial (7 vs 4.8 months), which may be explained by the use different of treatment lines between trials (minimum three lines vs four lines), but the OS was similar in our study. A recent retrospective analysis also aimed to investigate the role of palbociclib among heavily treated (more than 4 previous CT lines) patients with $\mathrm{mBC}$. The authors of that analysis reported the utility of palbociclib among 118 hormone receptor-positive/ HER2- patients with advanced BC. The clinical benefit rate was $47.5 \%$; overall response rate was $15.8 \%$; median PFS was 4.5 months; and median OS was 15.8 months. In terms of therapeutic efficacy, PFS and response rate were comparable with our results, but our results were again favorable. Hematological side effects were consistent with our trial: $89.7 \%$ developed neutropenia (grade $\geq 3$ in $56.8 \%$ ), and $5.1 \%$ experienced febrile neutropenia. However, dose reductions and discontinuation rates were higher in the prior trial than in our trial; $48.3 \%$ had dose decreases after side effects, and $3.4 \%$ had palbociclib discontinued due to toxicity (16).

In summary, our trial adds important information to the literature about the use of palbociclib among highly treated hormone receptor-positive/HER2 ${ }^{-}$patients with advanced BC. We demonstrated comparable PFS and OS rates among patients with advanced BC, and palbociclib was well tolerated except for febrile neutropenia among patients with such severe disease. The main limitation of our study is its retrospective nature and the relatively small number of patients. Additionally, we only determined PFS and OS, so we could not get any information about quality-of-life measures.

We demonstrated that the efficacy of palbociclib among heavily treated hormone receptor-positive/HER2 ${ }^{-}$patients with advanced $\mathrm{BC}$ was comparable and generally well tolerated among this population. Further randomized controlled studies with a larger number of patients is needed to confirm our findings and define patients who may benefit even in late-stage disease.

Conflict of Interest: No conflict of interest was declared by the authors.

Financial Disclosure: The authors declared that this study received no financial support.

\section{REFERENCES}

1. Ferlay J, Steliarova-Foucher E, Lortet-Tieulent J, Rosso S, Coebergh JW, Comber H, et al. Cancer incidence and mortality patterns in Europe: estimates for 40 countries in 2012. Eur J Cancer 2013;49:1374-403.
2. Boér K. Impact of palbociclib combinations on treatment of advanced estrogen receptor-positive/human epidermal growth factor 2-negative breast cancer. Onco Targets Ther 2016;9:6119-25.

3. Cardoso F, Senkus E, Costa A, Papadopoulos E, Aapro M, André F, et al. 4th ESOESMO International Consensus Guidelines for Advanced Breast Cancer (ABC 4). Ann Oncol 2018;29:1634-57.

4. Gradishar WJ, Anderson BO, Balassanian R, Blair SL, Burstein HJ, Cyr A, et al Breast Cancer, Version 4.2017, NCCN Clinical Practice guidelines in Oncology. J Natl Compr Canc Netw 2018;16:310-20.

5. Osborne CK, Schiff R. Mechanisms of endocrine resistance in breast cancer. Annu Rev Med 2011;62:233-47.

6. Maurer C, Martel S, Zardavas D, Ignatiadis M. New agents for endocrine resistance in breast cancer. Breast 2017;34:1-11.

7. Augereau P, Patsouris A, Bourbouloux E, Gourmelon C, Abadie Lacourtoisie S, Berton Rigaud D, et al. Hormonoresistance in advanced breast cancer: a new revolution in endocrine therapy. Ther Adv Med Oncol 2017;9:335-46.

8. Vidula N, Rugo HS. Cyclin-dependent kinase $4 / 6$ inhibitors for the treatment of breast cancer: a review of preclinical and clinical data. Clin Breast Cancer 2016;16:8-17.

9. Turner NC, Ro J, André F, Loi S, Verma S, Iwata H, et al. Palbociclib in hormonereceptor-positive advanced breast cancer. N Engl J Med 2015;373:209-19.

10. Cristofanilli M, Turner NC, Bondarenko I, Ro J, Im SA, Masuda N, et al. Fulvestrant plus palbociclib versus fulvestrant plus placebo for treatment of hormone-receptorpositive, HER2-negative metastatic breast cancer that progressed on previous endocrine therapy (PALOMA-3): final analysis of the multicentre, double-blind, phase 3 randomised controlled trial. Lancet Oncol 2019;17:425-39.

11. Sledge GW Jr, Toi M, Neven P, Sohn J, Inoue K, Pivot X, et al. MONARCH 2: abemaciclib in combination with fulvestrant in women with HR+/HER2-advanced breast cancer who had progressed while receiving endocrine therapy. J Clin Oncol 2017;35:2875-84.

12. Hortobagyi GN, Stemmer SM, Burris HA, Yap YS, Sonke GS, Paluch-Shimon S, et al. Ribociclib as first-line therapy for HR-positive, advanced breast cancer. N Engl J Med 2016;375:1738-48.

13. Finn RS, Crown JP, Lang I, Boer K, Bondarenko IM, Kulyk SO, et al. The cyclindependent kinase $4 / 6$ inhibitor palbociclib in combination with letrozole versus letrozole alone as first-line treatment of oestrogen receptor-positive, HER2-negative, advanced breast cancer (PALOMA-1/TRIO-18): a randomised Phase 2 study. Lancet Oncol 2014; 16:25-35.

14. Finn RS, Martin M, Rugo HS, Jones S, Im SA, Gelmon K, et al. Palbociclib and letrozole in advanced breast cancer. N Engl J Med 2016;375:1925-36.

15. Ban M, Miše BP, Majić A, Dražić I, Vrdoljak E. Efficacy and safety of palbociclib in heavily pretreated patients with HR+/HER2- metastatic breast cancer. Future Oncol 2018;14:537-44

16. Battisti NML, Kingston B, King J, Denton A, Waters S, Sita-Lumsden A, et al Palbociclib and endocrine therapy in heavily pretreated hormone receptor-positive HER2-negative advanced breast cancer: the UK Compassionate Access Programme experience. Breast Cancer Res Treat 2019;174:731-40. 